Who Gets the Goods?

\title{
A General Equilibrium Perspective on Food Aid in Mozambique
}

Arndt, Thomas Channing; Tarp, Finn

Published in:

Food Policy

Publication date:

2001

Citation for published version (APA):

Arndt, T. C., \& Tarp, F. (2001). Who Gets the Goods? A General Equilibrium Perspective on Food Aid in Mozambique. Food Policy, 26(2). 


\title{
Who Gets the Goods?
}

\section{A General Equilibrium Perspective on Food Aid in Mozambique}

\author{
Channing Arndt \\ Department of Agricultural Economics \\ Purdue University \\ Finn Tarp \\ Institute of Economics \\ University of Copenhagen
}

Corresponding author: Channing Arndt, Department of Agricultural Economics, 1145 Krannert Bldg., Purdue University, West Lafayette, IN 47907. Phone \# 765 494-5837, Fax \# 765 496-1224. Arndt@agecon.purdue.edu

Finn Tarp, Institute of Economics, University of Copenhagen, Studiestraede 6, DK-1455, Copenhagen K, Denmark. Finn.Tarp@econ.ku.dk.

\begin{abstract}
We employ a computable general equilibrium approach to examine the effects of alternative food aid distribution schemes for drought-response food aid to Mozambique. Alternative schemes have very distinct impacts on household welfare and prices. Compared with monetization of food aid by government, direct distribution to households (by population shares) strongly benefits rural households. Even assuming that government cannot target food aid strictly at drought-stricken rural people, our results indicate that, when improving household welfare is the primary goal of the food aid, direct distribution of food aid to households is preferred.
\end{abstract}




\section{Who Gets the Goods?}

\section{A General Equilibrium Perspective on Food Aid in Mozambique}

\section{Introduction}

Even though food aid (surveyed by Maxwell and Singer, 1979) has progressively declined as a share of total official development assistance from over $15 \%$ in the early 1970 s to less than $5 \%$ in the 1990 s, food aid has always been a controversial form of aid. It has generated debate, and volumes have been written. Much of this literature focuses on the political economy of food aid and whether food aid is "additional" (e.g., Colding and Pinstrup-Andersen, 1999; Ruttan, 1993); the impacts of food aid on agricultural production in the recipient country (e.g., Barrett, 1998; Isenman and Singer, 1993); and the real cost of food aid relative to other forms of development assistance (e.g., Clay, Dhiri, and Benson, 1996). A second strand of literature examines monetization-- whether food aid, particularly project or emergency, should be sold or distributed to consumers directly (e.g., Dorosh and Haggblade, 1997; Maxwell and Templer, 1994; Reutlinger, 1984).

Questions regarding the impact of food aid are typically, and appropriately, posed and analyzed in a partial equilibrium context. Nevertheless, general equilibrium effects of food aid are widely acknowledged to exist and to be important. The analytics of food aid in general equilibrium have, for example, been traced out by Bhagwati (1985). However, despite vastly increased capacity to conduct applied or computable general equilibrium (CGE) analysis in recent years, relatively little CGE analysis has been conducted on food aid issues. The CGE analyses conducted to date have generally focused on assessment of food aid needs (Riaz, 1992; 
Sadoulet and de Janry, 1992). The present article seeks to contribute to the debate regarding monetization of food aid using a general equilibrium approach. Specifically, the general equilibrium effects of alternative distribution schemes for food aid following a drought are examined for the case of Mozambique. We find that different distribution schemes (e.g., who takes possession of the food for either direct consumption or resale) have very distinct general equilibrium effects.

The remainder of this paper is structured as followed. Section 2 provides background on food aid to Mozambique. Section 3 presents the CGE model employed with special attention to unique features of the model and the treatment of food aid. Section 4 discusses simulations and results. A final section concludes.

\section{Background on Mozambique}

The population of Mozambique is predominantly rural and overwhelmingly poor. Analysis of data from the 1996-97 marketing year (a good production year) revealed that $64 \%$ of the rural population had insufficient calories available to meet the requirements of household members (MPF/UEM/IFPRI, 1998). Primary agriculture accounts for about $25 \%$ of gross domestic product (GDP) (NIS, 1998), rural households are heavily dependent on agriculture for income (Benfica, 1998), and home consumption of own agricultural production accounts for $40 \%$ of total expenditure by rural households (Arndt, Jensen, Robinson, and Tarp, 2000). In addition, climate induced variability in agricultural production can be large (Rojas and Amade, 1997).

In this environment, the economic impacts of drought can be substantial; and food aid can play a significant role in palliating the negative effects of drought. To give an extreme example, due to the combined effects of war and drought, the Mozambican population essentially subsisted 
on food aid in 1992 (Tschirley, Donovan, and Weber, 1996). Since that time, the return of peace and good rains have helped to dramatically increase agricultural production and reduce food imports. Trends in production and imports of maize are shown in Figure 1. Import data are not yet available for 1998 and 1999. However, the Southern African Development Community Food Security Unit projects a mild maize surplus for the 1999-2000 marketing year. Food aid volumes have declined commensurately with the increases in production and decreases in imports. ${ }^{1}$

While one certainly hopes that the desperate situation encountered in 1992 will not return, drought is almost certain to strike again in the relatively near future. Following a widespread and reasonably severe drought, food imports will reappear on a large scale. It is also reasonable to expect that a substantial share of these imports will arrive in the form of food aid.

\section{The CGE Model}

In many ways, the model employed for this analysis is quite standard. Excellent descriptions of standard neoclassical CGE models are available in Dervis, de Melo, and Robinson (1982) and Devarajan, Go, Lewis, Robinson, and Sinko (1997). However, the Mozambique model exhibits a number of important departures from standard neoclassical CGE models. These departures, plus a brief description of other model characteristics, are in focus in this section. The full set of model equations is available upon request.

\section{$\underline{\text { Marketing Margins }}$}

${ }^{1}$ Mozambique remains a structural importer of wheat and rice. These imports represent about $15 \%$ of total domestic supply of cereals (SADC/FSU, 1999). 
Margins between the price paid at the source of supply, such as the farm gate, and the price paid by the final consumer are often very large. High marketing costs reflect: large distances between production and consumption centers, poor infrastructure, high costs of capital which result in high costs of holding inventories, and high risks associated with trading activities combined with limited opportunities for diversification. They are particularly large in primary agriculture and primary agricultural processing. In the 1995 social accounting matrix on which the CGE model is based, these two sectors account for $70 \%$ of total spending on margin services. In the model, marketing margins are carefully accounted for. In addition, marketing margin rates vary depending upon whether the product is produced and sold domestically, exported, or imported. These margins are discussed in more detail in Arndt, Jensen, Robinson, and Tarp (2000).

\section{$\underline{\text { Home consumption }}$}

The presence of high marketing margins implies a significant wedge between the factory/farm gate sales price and the purchase price for consumption of a given commodity. Rather than sell at a low price and purchase at a high price, households, particularly rural agricultural households, can opt to consume at least some of what they produce. In this manner, marketing margins are avoided.

Home and marketed consumption of all commodities is captured in a linear expenditure system (LES) formulation. Home and marketed commodities are treated as separate commodities in the system. So, for example, home consumed cassava differs from marketed cassava. In this formulation, supernumerary income, defined as household income less savings, taxes, and the cost of minimum consumption levels of both home and marketed commodities, is allocated 
across commodities via share parameters. Elasticities of substitution between home and marketed commodities are determined by minimum consumption parameters. If these minimum consumption parameters are set to zero, the LES formulation collapses to a Cobb-Douglas utility function with elasticities of substitution equal to one.

The parameters of the utility function (estimation described in Arndt, Robinson, and Tarp, 1999), set the quantity of home consumption to be relatively insensitive to changes in price through relatively high values on the minimum consumption parameters, especially for rural households. This implies that marketed production of agricultural commodities will tend to be more variable than total production volume as rural households will sell more surplus in good years and retain a greater share of harvest to meet family needs in poor years.

While large marketing margins and high shares of home consumption are common features of African economies, this is to the authors' knowledge the first CGE model of an African economy that simultaneously captures these features.

\section{$\underline{\text { Food Aid }}$}

Food aid enters the model through the composite commodity market clearing conditions. It simply increases composite commodity supply. While the machinery of the model would allow for increased supply of any commodity in the model through food aid, food aid in Mozambique has almost invariably arrived in the form of grains. Food aid is thus modeled as an increase in the supply of grains.

Under this formulation, food aid represents an increase in the supply of goods without any associated real resource costs of production or delivery. As such, the model takes the perspective of the recipient who simply receives an increased supply of food (in the form of grain). This 
formulation is attractive in that it is simple and conforms to the basic vision of the purpose of food aid. A potential disadvantage of the formulation is that marketing margins are avoided. As emphasized above, receipt and distribution of goods, such as grains, entails real resource costs. The model does not capture any real resource costs associated with receipt and distribution of food aid.

While imperfect, this approach is probably the best available option. Domestic real resource costs associated with receipt and distribution of food aid are not known. They are likely to be considerably below the domestic real resource marketing cost for locally produced or privately imported products for two reasons. First, food aid distributors tap international credit markets and do not have commercial motivations. As a result, the costs of working capital and risk considerations, both of which are mentioned above as major contributors to the marketing margins, do not apply. Second, distribution infrastructure, such as trucks, often arrives with the food aid allowing (all too frequently according to critics) food aid providers to sidestep local marketing services (Colding and Pinstrup-Andersen, 2000). ${ }^{2}$ These considerations, combined with the advantages of simplicity, make the current formulation attractive.

Once the food aid enters the system, careful consideration is given to who takes ownership. The food aid is valued at market prices. If, for example, the government takes ownership of the food aid, it can sell the food aid and use the resulting revenue in any manner it chooses. ${ }^{3}$ If, on

\footnotetext{
${ }^{2}$ Note that we are not arguing that it is cheaper or better, from the donor perspective, to sidestep local credit and distribution channels. We are merely stating that it is done. An extreme example is the airlifting of grain to drought struck regions. From the donor perspective, this operation is very expensive. From the recipient perspective, grain simply appears in the region with practically no domestic resource costs associated with receipt and distribution.

${ }^{3}$ Donors may of course decide to play a role here, but we assume that this does not change
} 
the other hand, the food aid is distributed directly to households, it can either be consumed directly or sold in order to purchase other goods.

\section{Other Features Plus Parameter Estimation and Model Validation}

Two types of labor, agricultural and non-agricultural, are present in the model. Due to the short run nature of the simulations, capital is fixed in each sector; and agricultural labor is fixed by agricultural activity. For agricultural activities, this amounts to assuming that a production plan is decided upon prior to the onset of drought. Once the drought begins, agents in the agricultural sector, particularly the smallholders who dominate production, have very little opportunity to react. Production technology is Cobb-Douglas in value added. This value added aggregate combines with intermediate products in a Leontief fashion. The model contains a rural and an urban household. The rural household gains income primarily from sale of agricultural labor while the urban household gains income primarily from sale of non-agricultural labor and capital rental. The consumer price index, inclusive of the prices of home consumed goods, is the numeraire. Government recurrent and investment spending is set at a constant share of absorption (except when revenue from food aid sales accrues to the government). The model is closed by fixing the value of foreign currency inflows and allowing the exchange rate to adjust endogenously. This closure is the most logical due to the importance of aid flows.

Base data for the model is derived from a 1995 social accounting matrix (SAM) for Mozambique (Arndt, Cruz, Jensen, Robinson, and Tarp, 1998). The SAM contains detailed primary agriculture, primary agriculture processing, and marketing cost accounts. Simulations are conducted on a slightly aggregated SAM containing 10 primary product activities, three primary

in any way the use of the revenue. This seems reasonable in view of past experience. 
agriculture processing activities, five industrial activities, and 10 service activities. Excepting the commerce activity, to which there is no corresponding commodity, activities and commodities correspond one to one.

A novel maximum entropy approach was employed to validate the model and to estimate behavioral parameters (Arndt, Robinson, and Tarp, 1999). Briefly, the full CGE model was backcasted to follow the historical record for the period 1996 to 1992 (five observations). Import (CES) and export (CET) parameters, LES preference parameters, and technical change parameters were chosen which permitted the model to best reproduce the historical record conditional on a set of prior distributions for these parameters. Measures of goodness of fit indicated that the model is capable of reproducing many of the salient aspects of recent economic history in Mozambique.

In order to reduce computational burden, a fairly aggregate version of the model was employed in the estimation/validation procedure. In parameterizing the more disaggregate model employed here, the parameter value estimated for an aggregate is assigned to all of its components. For example, an Armington import elasticity was estimated for the aggregate food crops. Commodities in this aggregation such as grains and other basic food crops are therefore all assumed to have the same import elasticity in the simulations conducted here.

\section{Simulations and Results}

Table 1 lists the simulations presented. Experiment 1 simulates a drought in the absence of any food aid for drought relief. Experiment 2 combines drought with food aid. Food aid volumes amount to nearly $60 \%$ of the volume of grain imports observed in experiment 1 or $85 \%$ of the volume of grain imports observed in 1995, the base year for the SAM. The food aid imports are 
monetized at market prices and the revenue is delivered to government. Government is assumed to spend the food aid revenue on recurrent and investment expenditure in accordance with observed spending shares. ${ }^{4}$ Experiment 3 is the same as experiment 2 except that the food aid is delivered directly to rural and urban households according to population shares. ${ }^{5}$

In simulating drought in Mozambique, it is worthwhile to note that agricultural production is essentially the process of converting labor into agricultural goods. The vast majority of production is smallholder based using rudimentary technology. Input use is essentially confined to seed, capital involves rudimentary tools only, and land is generally abundant. ${ }^{6}$ In this environment, drought can be adequately simulated by shocking technology in a Hicks-neutral fashion. The exact declines in technology are listed in Table 2. Since labor and capital are fixed by agricultural activity, the technology declines shown in Table 2 translate directly into production declines. ${ }^{7}$

The figures in Table 2 reflect existing time series data on production as analyzed by Bacou (2000), the technology parameters estimated by Arndt, Robinson, and Tarp (1999) for agriculture

${ }^{4}$ Other spending schemes are, of course, possible. Note that, monetization by government with the proceeds distributed to households is, in this model, tantamount to direct distribution to households.

${ }^{5}$ The simulations assume a 70\% rural and 30\% urban population split in accordance with the 1997 population census.

${ }^{6}$ There is evidence of land scarcity in some areas (MAP/MSU, 1992).

${ }^{7}$ The cotton sector receives some special treatment. National accounts data indicate that raw cotton is neither exported nor imported. The textile industry relies entirely on domestically produced cotton. As a result, demand for domestically produced cotton is extremely inelastic and changes in production result in substantial price movements. Perhaps because of this issue, textile firms have been granted monopsony power in purchasing raw cotton in predetermined "action zones". These monopsonies are regulated (and partially owned) by the government. Prices for raw cotton are contracted in advance of the growing season. To reflect this environment, we assume that the producer price of cotton is fixed (relative to the CPI), and that textile firms maintain a stock of raw cotton in order to smooth out variability in production. 
in 1992 (a severe drought year) from their backcasting work, interviews with experts on Mozambican agriculture, and the judgement of the authors. The figures in Table 2 represent a weighted average agricultural productivity decline of $20 \%$.

Table 3 illustrates the macroeconomic effects of the shocks. As expected, the drought results in a decline in GDP in all scenarios. In experiment 1 (no food aid), a steep decline in home consumption, a more moderate decline in marketed consumption, and an increase in imports contribute to the decline in GDP. In order to finance the increased imports (primarily of food), exports must increase. This is possible since primary agriculture and processed food account for less than $15 \%$ of total exports (fish and services comprise the bulk of exports). Due to a sizeable trade deficit, the proportionate rise in exports must exceed the rise in imports in order to maintain external balance. Note that, in experiment 2 where government receives revenue from monetized, the share of government in GDP expands.

Recall that the agricultural share in GDP is about $25 \%$ and that the decline in agricultural productivity is about $20 \%$. This implies a GDP decline of about 5\%, which is the GDP decline generated by the model. Production in non-agricultural sectors changes relatively little with export oriented tending to expand slightly. This lack of spillover of drought induced GDP decline into non-agricultural sectors is consistent with the work of Benson and Clay (1998) who find, in a cross country analysis focused on Africa, that the GDP effects of drought in countries with relatively low levels of development, such as Mozambique, tend to be confined to the agricultural sector due to relatively weak links between primary agriculture and non-agricultural 
sectors in the input/output matrix. As a result, the drought induced decline in agriculture is relatively isolated and does not spill over into other sectors. ${ }^{8}$

The consumer price index is held fixed at a constant level in the simulations (it is the numeraire). Consequently, the absorption figures presented at the bottom of Table 3 can be used as a measure of aggregate welfare. As expected, the addition of food aid does not change GDP substantially (the small change observed is due to changes in output composition). However, food aid does increase welfare as measured by nominal absorption deflated by the consumer price index. Based on this measure alone, monetized food aid (experiment 2) is preferred as it results in the smallest drought induced decline in absorption/welfare. However, investment and government spending are significant components of absorption; and the focus in drought years is on household consumption.

\footnotetext{
${ }^{8}$ The existence of raw cotton stocks also attenuates the connection between agricultural and non-agricultural sectors.
} 
Table 4 shows equivalent variation (EV) on consumption for urban and rural households for the three experiments. By this measure, the ranking is reversed. Household welfare, as measured by equivalent variation on consumption, is substantially higher when food aid is distributed directly to households (experiment 3) as opposed to monetized by government (experiment 2). The differential effects of alternative food aid distribution schemes on the components of total absorption drive this result on aggregate household welfare. When food aid is distributed to households, the first order incidence of the food aid accrues directly to households and the household share of total absorption expands with concomitant impacts on household welfare. ${ }^{9}$

In order to explain the differences in welfare results between households (as well as the differences in the impacts on aggregate absorption across experiments), grain import volumes and relative price effects must be examined. Grain import volumes are shown in Table 5. Note that food aid primarily substitutes for commercial imports. The total supply of grain available (domestic production, plus imports, plus food aid) varies, but not dramatically, across the experiments.

The changes in agricultural terms of trade, using the price of value added in agriculture relative to non-agriculture, are depicted in Table 6. Following a drought (experiment 1), agricultural terms of trade increase dramatically reflecting the contraction of agricultural production. Large budget shares for food, especially home consumption, imply that rural household welfare decreases despite the improved terms of trade in the sale of their agricultural

\footnotetext{
${ }^{9}$ Ordinarily, one strives to prevent shifts in the composition of absorption from contaminating welfare analysis. However, in this short run analysis of the implications of drought
} 
production. Urban household welfare declines primarily due to higher prices for agricultural products.

When food aid in the form of grains appears as in experiment 2 , the effect is to diminish the agricultural terms of trade relative to experiment 1 . The producer price of grains, which rises by $28 \%$ in experiment 1 , but only by $16 \%$ in experiment 2 , is the main reason for the more modest increase in the agricultural terms of trade. Prices of other agricultural products rise very slightly between experiments 1 and 2 . Due to these price shifts, the benefits of food aid tend to accrue to urban households (Table 4). In sharp contrast, when food aid is distributed directly to households, agricultural terms of trade actually increase. The difference in impact on agricultural terms of trade between experiments 2 and 3 is very substantial.

and food aid, these compositional shifts are in focus. 
The differential impact on agricultural terms of trade between experiments 2 and 3 arises from the very different marginal budget shares between households and government. Urban and rural households spend respectively $64 \%$ and $88 \%$ of an additional unit of income directed to consumption (e.g., an increment to supernumerary income) on primary agricultural commodities and processed foods. On the other hand, only $5 \%$ of government spending on commodities is directed towards primary agricultural commodities and processed foods. By assumption, marginal and average government budget shares are equated in the model formulation. Consequently, the first order impact of monetized food aid with the revenue given to government is an increase in spending on non-agricultural goods. The opposite occurs when food aid is given directly to households. The income increases resulting from food aid are directed overwhelmingly towards agricultural goods. These differential spending patterns affect the desired composition of total absorption and strongly influence relative prices. ${ }^{10}$

\footnotetext{
${ }^{10}$ The difference in price effects between experiments 2 and 3 also help to explain the difference in effects on absorption observed in Table 3. Absorption in Table 3 is deflated by the CPI. The CPI is composed primarily of food. If the CPI were not the numeraire, it would have a higher value in experiment 3 compared with experiment 2. Since the CPI is the numeraire, other prices must decline. This change in prices relative to the CPI explains the greater decline in absorption in experiment 3 compared with experiment 2 .
} 
The effects of these differentials in spending patterns can also be seen in the figures on grain import volumes shown in Table 5. In the absence of food aid, drought drives up grain import volumes by nearly $50 \%$ relative to the base. When food aid is delivered and monetized with the proceeds accruing to government as in experiment 2 , the income/welfare impacts on the primary demanders of grain, households (particularly rural households), are relatively small. As a result, grain demand is essentially constant and food aid mainly serves to displace imports. Total grain import volume remains essentially the same (commercial imports plus food aid). ${ }^{11}$ When the food aid is delivered to households as in experiment 3, household income/welfare expands and demand for grain expands along with it. Imports of grain in experiment 3 are $5 \%$ greater than in experiment $1 .^{12}$ The increase comes through the food aid transfer induced income expansion which stimulates household demand. In the real world, targeting of food aid distributions to particularly hard hit members of the population, where effective demand is lowest, would likely result in a larger increase in food supply relative to a no food aid scenario (e.g., further reductions in import displacement).

Table 7 illustrates the impacts on factor prices. These results follow logically from the preceding discussion. Drought (experiment 1) reduces returns to all factors relative to the CPI. Due to the improvements in agricultural terms of trade, agricultural labor experiences the mildest

\footnotetext{
${ }^{11}$ Since food aid enters as composite commodity and imports must combine with domestic production in order to form the composite commodity, we are technically adding together different products or adding together apples and oranges. A more apt analogy would be adding together white and yellow maize, which does, in fact, give a good idea of total maize availability. Nevertheless, despite the relatively high Arminton elasticity, this product differentiation between imported and domestic grains drives the relative price shifts observed for grains between experiments 1 and 2 .

${ }^{12}$ Imports of other food commodities also increase.
} 
factor price decline relative to other factors. When food aid is monetized and the proceeds spent by government (experiment 2), the drought induced agricultural terms of trade improvement is moderated. As a result, returns to agricultural labor decline and returns to non-agricultural labor and capital increase relative to experiment 1 . When food aid is delivered directly to households in experiment 3 , the improvements in agricultural terms of trade, relative to experiments 1 and 2 , result in increases in returns to agricultural labor and decreases in returns to non-agricultural labor and capital relative to both preceding experiments. In fact, in experiment 3 , agricultural labor wages decline very little relative to the base situation with no drought. 


\section{Conclusions}

This paper has examined the effects of alternative food aid distribution schemes for drought-response food aid to Mozambique. Alternative distribution schemes have very distinct impacts on household welfare and prices, notably the relative price of agricultural goods. Compared with monetization of food aid by government, direct distribution to households (done by population shares in the experiments) strongly benefits rural households for two reasons. First, when households take ownership of the food aid, they experience the first order impact of the resource transfer. Second, since households direct the large majority of any increment to income to the purchase of agricultural goods, the increase in household income generated by the food aid expands the demand for agricultural goods. Alternatively viewed, when households derive income from food aid, the desired components of nominal absorption shift towards agricultural products. As a result, agricultural terms of trade improve (even relative to the drought without food aid scenario), which further benefits rural households. Despite the maintained assumption that government cannot target food aid strictly at drought-stricken rural people, these results indicate that, when improving household welfare for the poorest is the primary goal of food aid, direct distribution of food aid to households is preferred. 


\section{References}

Arndt, C., S. Robinson, and F. Tarp, 1999. Parameter Estimation for a Computable General Equilibrium Model: A Maximum Entropy Approach. International Food Policy Research Institute, Trade and Macroeconomics Division Discussion Paper No. 40.

Arndt, C., A. Cruz, H.T. Jensen, S. Robinson, and F. Tarp, 1998. Social Accounting Matrices for Mozambique: 1994-95, International Food Policy Research Institute, Trade and Macroeconomics Division Paper No. 28.

Arndt, C., H. T. Jensen, S. Robinson, and F. Tarp, 2000. Marketing Margins and Agricultural Technology in Mozambique, Forthcoming in the Journal of Development Studies.

Bacou, M., 2000. Unpublished thesis. Dept. of Agricultural Economics, Purdue University.

Barrett, C. B. 1998. Food Aid: Is it Development Assistance, Trade Promotion, Both, or Neither? American Journal of Agricultural Economics, Vol. 80, (3), 566-571.

Benfica, R., M., 1998. Analysis of the Contributions of Micro and Small Enterprises to Rural Household Income in Central and Northern Mozambique, Master's thesis, Department of Agricultural Economics, Michigan State University. 
Benson, C. and Clay, E., 1998. The Impact of Drought on Sub-Saharan African Economies - A Preliminary Examination, World Bank Technical Paper no. 401.

Bhagwati, J., 1985. Food Aid, Agricultural Production and Welfare, in Gene Grossman (ed.) Dependence and Interdependence, Development Economics series, vol. 2, Cambridge, Mass.: MIT Press; Oxford: Blackwell, 1985, ,. 285-97.

Clay, E.S., Dhiri, and C. Benson, 1996. Joint Evaluation of European Union Programme Food Aid: Synthesis Report and Summary of Synthesis Report. A Study Commissioned by the Working Group of Heads of Evaluation Service (Development) of the European Union. London: Overseas Development Institute.

Colding, B., and P. Pinstrup-Andersen, 2000. Food Aid as a Development Assistance Instrument: Past, Present, and Future, in Finn Tarp (ed.) Foreign Aid and Development: Lessons Learnt and Directions for the Future. London: Routledge.

Devarajan, S.D.S. Go, J.D. Lewis, S. Robinson and P. Sinko, 1997. Simple general equilibrium modeling in applied methods for trade policy analysis, in J.F. Francois and K.A. Reinert (eds.) Applied Methods for Trade Policy Analysis: A Handbook. Cambridge: Cambridge University Press. 
Dervis, K., J. de Melo and S. Robinson, 1982. General equilibrium models for development policy. New York: Cambridge University Press.

Dorosh, P. A., and S. Haggblade, 1997. Shifting Sands: The Changing Case for Monetizing Project Food Aid in Bangladesh, World Development, Vol. 25, (12), 2093-2104.

Isenman, P. J., and H. W. Singer, 1993. Food Aid: Disincentive Effects and Their Policy Implications, in V. W. Ruttan (ed.) Why Food Aid. Baltimore and London: The Johns Hopkins University Press, ,. 99-122.

MAP/MSU, 1992. The Determinants of Household Income and Consumption in Rural Nampula Province: Implications for Food Security and Agricultural Policy Reform, Working Paper No. 6E, Directorate of Economics, Ministry of Agriculture and Fisheries, Maputo.

Maxwell, S.J., and G. Templer, 1994. The Monetization of Project and Emergency Food Aid: Project-Level Efficiency First! Food Policy, Vol. 19,(1), 9-15.

Maxwell, S. J., and H. W. Singer, 1979. Food Aid to Developing Countries: A Survey, World Development, Vol. 7, (3), 225-47. 
MPF/UEM/IFPRI, 1998. National Household Survey, Ministry of Planning and Finance, University Eduardo Mondlane, International Food Policy Research Institute, Maputo, Mozambique.

NIS, 1998. National accounts data in electronic form, National Institute of Statistics, Maputo, Mozambique.

Reutlinger, S., 1984. Project Food Aid and Equitable Growth: Income-Transfer Efficiency First! World Development, Vol. 12, (9), 901-911.

Riaz, Khalid, 1992. Food Aid as a Development Resource: Performance, Potential, and Prospects: Appendix 7.A: Methodologies Used to Assess Food Aid Need, in Fletcher-Lehman-B. (ed.) World food in the 1990s: Production, trade, and aid. Boulder and Oxford: Westview Press, 266-78.

Rojas, O., and J. Amade, 1997. O Impacto de El Nino-Oscilação e sua Aplicação na Seguarança Alimentar, Maputo, Mozambique, DINA/MAP.

Ruttan, V. W. 1993. The Politics of U.S. Food Aid Policy: a Historical Review, in V. W. Ruttan (ed.) Why Food Aid? Baltimore and London: The Johns Hopkins University Press, ,. 2-36. 
Sadoulet, E., and A. de Janvry, 1992. Agricultural Trade Liberalization and Low Income Countries: A General Equilibrium-Multimarket Approach, American Journal of Agricultural Economics, Vol. 74, (2), 268-80.

SADC/FSU, 1999. Web data. http://www.zimbabwe.net/sadc-fanr/intro.htm.

Tschirley, D., C. Donovan, and M. T. Weber, 1996. Food Aid and Food Markets: Lessons from Mozambique. Food Policy, Vol. 21, (2), 189-209. 
Figure 1: Maize production and imports 
Table 1: Simulations and labels for subsequent tables.

\begin{tabular}{|ll|}
\hline Base & Base 1995 Data \\
Exp. 1 & Drought without food aid \\
Exp. 2 & Drought with monetized food aid and revenue to government \\
Exp. 3 & Drought with food aid distributed directly to households \\
\hline
\end{tabular}


Table 2: Declines in technology ${ }^{1}$ used to simulate drought.

\begin{tabular}{ll}
\hline Grain & 0.67 \\
Raw cashew & 0.85 \\
Raw cotton & 0.93 \\
Other exports & 0.85 \\
Basic food crops & 0.67 \\
Livestock & 0.75 \\
Forestry & 0.85 \\
\hline
\end{tabular}

${ }^{1}$ Technology declines are assumed to be Hicks-neutral. Since resource use is fixed in each sector, these technology changes translate directly into production declines. 
Table 3: Components of real GDP and absorption (welfare).

\begin{tabular}{|lrrrr|}
\hline & $100{\text { bn } \mathrm{Mt}^{1}}^{1}$ Percent deviation from base values \\
& Base & Exp. 1 & Exp. 2 & Exp. 3 \\
& & & & \\
\hline Exports & 32.7 & 4.4 & 0.2 & 1.6 \\
Imports & 83.9 & 1.9 & 4.9 & 5.5 \\
Home Consumption & 32.6 & -16.1 & -14.9 & -13.7 \\
Marketed Consumption & 106.8 & -3.6 & -3.0 & -0.6 \\
Recurrent Govt. & 16.8 & 0.6 & 10.5 & 2.4 \\
Non-Govt. Organizations & 5.5 & 1.6 & 0.6 & 0.9 \\
Investment & 61.5 & 0.7 & 3.2 & 0.5 \\
Real GDP & 172.1 & -5.0 & -4.9 & -4.9 \\
& & & & \\
Absorption & 223.3 & -5.9 & -3.7 & -4.6 \\
& & & & \\
\hline
\end{tabular}

${ }^{1}$ The metical (Mt) is the local currency. The exchange rate was 8,890 Mt/US\$ in 1995. 
Table 4: Equivalent variation on consumption

\begin{tabular}{|lcccc|}
\hline & \multicolumn{5}{c|}{ Percent of base consumption } \\
& Base & Exp. 1 & Exp. 2 & Exp. 3 \\
\hline Urban & 0.0 & -4.3 & -3.4 & -2.6 \\
Rural & 0.0 & -9.8 & -9.2 & -5.7 \\
Total & 0.0 & -6.9 & -6.1 & -4.1 \\
\hline
\end{tabular}


Table 5: Grain and food aid imports (in units of volume)

\begin{tabular}{|lcccr|}
\hline & Base & Exp. 1 & Exp. 2 & Exp. 3 \\
\hline Grain food aid volume & 0.0 & 0.0 & 3.5 & 3.5 \\
Volume of grain imports & 4.1 & 6.0 & 2.5 & 2.8 \\
\hline
\end{tabular}


Table 6: Agricultural terms of trade

\begin{tabular}{|lcccc|}
\hline & Index & \multicolumn{2}{c|}{ Percent deviation from base values } \\
& Base & Exp. 1 & Exp. 2 & Exp. 3 \\
\hline Value added & 100.0 & 31.6 & 26.5 & 35.6 \\
\hline
\end{tabular}


Table 7: Factor prices

\begin{tabular}{|lcccc|}
\hline & Index & \multicolumn{4}{c|}{ Percent deviation from base values } \\
& Base & Exp. 1 & Exp. 2 & Exp. 3 \\
\hline Agricultural labor & 1.0 & -2.5 & -4.2 & -0.2 \\
Non-Agricultural labor & 1.0 & -7.3 & -4.9 & -7.9 \\
Capital & 1.0 & -9.2 & -8.3 & -9.8 \\
\hline
\end{tabular}

